\title{
Michel Crouzet, M. Myself ou La Vie de Stendhal
}

\section{Michel Arrous}

\section{(2) OpenEdition}

\section{Journals}

\section{Édition électronique}

URL : https://journals.openedition.org/studifrancesi/3133

DOI : 10.4000/studifrancesi.3133

ISSN : 2427-5856

\section{Éditeur}

Rosenberg \& Sellier

\section{Édition imprimée}

Date de publication : 1 juillet 2013

Pagination : 467-468

ISSN : 0039-2944

\section{Référence électronique}

Michel Arrous, « Michel Crouzet, M. Myself ou La Vie de Stendhal », Studi Francesi [En ligne], 170 (LVII |

II) | 2013, mis en ligne le 30 novembre 2015, consulté le 02 février 2023. URL : http://

journals.openedition.org/studifrancesi/3133; DOI : https://doi.org/10.4000/studifrancesi.3133

\section{Ce document a été généré automatiquement le 2 février 2023.}

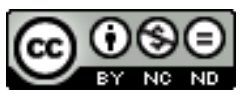

Creative Commons - Attribution - Pas d'Utilisation Commerciale - Pas de Modification 4.0 International - CC BY-NC-ND 4.0

https://creativecommons.org/licenses/by-nc-nd/4.0/ 


\title{
Michel Crouzet, M. Myself ou La Vie de Stendhal
}

\author{
Michel Arrous
}

\section{RÉFÉRENCE}

Michel Crouzet, M. Myself ou La Vie de Stendhal, nouvelle version, Paris, Éditions Kimé, 2012, pp. 728.

Jugé insurpassable, le Stendhal ou Monsieur moi-même (Flammarion, «Grandes biographies», 1990; réédition Flammarion, «Biographies historiques», 1999, 797 p.), va connaître une autre vie grâce à cette version qui tient compte des découvertes stendhaliennes récentes. Si la narration a par endroits été réorganisée, le découpage chronologique et thématique maintenu et plus précisément indiqué, il s'agit bien d'une nouvelle version, d'un enrichissement que quelques exemples suffiront à illustrer: les rapports avec le père, l'emprise pédagogique de l'abbé Raillane qui «dirigeait la sensibilité, par la sensibilité, pouvoir doucereux et insinuant, redoutable par là», sur Henri «méconnu, étranger dans sa famille», ou bien sur le Stendhal de 1801 qui «ne sait pas dire ce qu'il a vécu, ou [qui] n'a pas encore vécu ce qu'il saura dire». De nombreuses additions nourrissent les pages sur les années d'apprentissage, sur HB philosophe, sur l'élève du cours Dugazon («Le théâtre envahit la réalité»). Il faudrait en dire autant du chapitre IV, "Au service de l'Empereur», particulièrement des pages consacrées à Stendhal administrateur où M. Crouzet épingle les «stendhaliens bien intentionnés qui ont cherché à démontrer que Stendhal a été un bon fonctionnaire», qui ont loué son «sérieux administratif», et même prétendu que son style relève de l'expérience bureaucratique; ou du passionnant chapitre VI («L'Ère Métilde») où l'on suit un Stendhal «fort éloigné du néant érotique des modernes». On relèvera aussi, dans les chapitres consacrés à l'affreux séjour qu'était Civitavecchia, l'analyse nouvelle du consulat comme véritable peine de relégation: «Qui aurait pu résider à Civitavecchia? Qui l'a jamais fait?». Et M. Crouzet de mettre les points sur les i: «La situation incongrue, absurde, insoutenable qui explique ses absences, c'est tout simplement 
qu'on ait nommé là ce consul d'exception dont la Monarchie de Juillet a été tellement embarrassée qu'elle s'en est débarrassée en le nommant à un poste indigne et impossible». Pages ponctuées d'heureuses et fortes formules: «Forcer un Stendhal à y résider relevait de la bêtise d'État». Envoyer Stendhal dans ce «consulat croupion», c'était signer l'intention de lui nuire. On retrouve là «le conflit inexpiable entre le pensant et le gouvernant, entre l'écrivain et le pouvoir». Mais, on le sait, et M. Crouzet le rappelle avec précision, Stendhal a pris son parti de la routine consulaire et a su y échapper. Le dernier chapitre («Une mort naturelle») contient lui aussi de nombreux suppléments sur la mort et la survie de cet «homme des cimes». La bibliographie a été mise à jour; en revanche, l'index fait toujours défaut. Il est vrai que la table des matières, fort détaillée, permet aisément de retrouver tel personnage ou tel moment dans cette somme stendhalienne. 